\title{
1. The puzzle of the commons
}

Commons are scarce resources that are subject to dissipation or congestion when their use is unrestrained or unrestricted. There are many types of commons: natural resources, the global environment, knowledge (Frischmann, Madison, and Strandburg 2014), electromagnetic spectrum (Hazlett 2008; Hazlett, Porter, and Smith 2011; Hazlett 2017; Bustamante et al. 2020), innovation (Potts 2019), communes (Mause 2008), and online communities (Harris 2018), to name a few. Our focus is on the resource commons (which includes natural resources such as forests, fisheries, groundwater aquifers, oil and gas reservoirs, and animal species) and the global commons (which refers primarily to the global environment). What distinguishes the resource and global commons is, first, the underlying danger of losing the resource in question and, second, the lesser role for technology in their governance.

When the resource and global commons are managed well, societies prosper. Well-managed commons provide livelihoods and opportunities to enjoy nature's wonders. Societies are built by transforming the commons into productive uses, as they provide lumber to build homes, food to sustain us, and energy to warm us. The air we breathe, and hence our health, requires us to care for the commons. When commons are managed poorly, economies collapse, livelihoods are lost, health declines, and we lose, sometimes forever, the things that we enjoy. Our argument is that the question of whether we get the good or bad outcomes is always a question of institutions.

The ultimate goal when considering the commons is always sustainability. Since the term sustainability has many meanings, it is necessary to first define the concept. Our preferred definition builds on the following, though for reasons we specify below it is necessary to include economic considerationsnet benefits - as part of sustainability. The World Commission on Environment and Development in 1987 defined sustainability as economic development that meets present needs without compromising the ability of future generations to meet their own needs - a definition focusing on resource depletion, rather than conservation and environmental protection (Portney 2015). Just sustainability means ensuring a better quality of life for all, now and in the future, in a just and equitable manner while supporting our ecosystems (Agyeman, Bullard, and Evans 2003). Many global indicators' names indicate the diversity of ways we can understand sustainability: Sustainable Development Goals and the Living Planet Index, to name a couple (Gale 2018), as well as measures of 
well-being beyond wealth, including the Human Development Index and the World Happiness Report.

We consider sustainability to be the ongoing balancing of economic considerations and ecological and environmental ones. For resource commons, sustainability consists of a continuum from conservation to preservation. Conservation is restraint of resource use across space (current users) and time (current and future users). Preservation means keeping resources in their natural state. Realistically, what societies tend to want is conservation because resources are valuable. For forests and fisheries, sustainability enables us to continue to use and enjoy the resources today and in the future by restricting how much of these resources we take in any given period. For minerals such as gold, diamonds, oil, and natural gas, sustainability requires avoiding conflict in the race to establish ownership and extract them and it requires investing the profits in ways that produce additional wealth. The reason why additional wealth is significant is that as we become richer, we become more willing and able to address commons problems, as we know from the enormous literature on postmaterial cultural shifts, which documents how environmental concerns become more prominent as societies become richer (Inglehart 1997). Globally, sustainability means appropriately pricing the consumptive activities that contribute to greenhouse gas (GHG) emissions and ocean pollution.

Sustainability also requires consideration of the cost of achieving environmental objectives since resources used for any purpose, even a noble one, could be used for something else. In our view, such a consideration will typically favor conservation and mitigation efforts. The reason is that there is no question that environmental and ecosystem services are enormously valuable. At the turn of the millennium, the global economic value of ecosystem services was much larger than the annual economic value produced in the global economy (Costanza et al. 1997), and the economic and noneconomic value created by the world's oceans constituted about 60 percent of the total economic value of the biosphere (Costanza 1999). The World Bank considers natural capital - along with produced capital, human capital, and foreign assets - a measure of wealth (Lange, Wodon, and Carey 2018). Another measure of consequences is that environmental quality relates to subjective well-being, including happiness: the 2020 World Happiness Report shows that human happiness falls when environmental quality declines (Helliwell et al. 2020). Thus, when we argue for consideration of economics, it is to ensure that we consider the question of the cost of achieving sustainability objectives, as an important goal for society is to choose the bundle of policies that achieves the goal of conservation, preservation, or pollution mitigation at the lowest cost.

Despite the value of commons, they are undervalued (Daily et al. 2000). The ongoing challenge is to foster institutions that align short-term private 
goals with long-run societal goals (Guerry et al. 2015). Mismanagement of commons is routine. The near extinction of American bison in the nineteenth century, continued clear-cutting of the world's rainforests, collapse of some of the world's inland and ocean fisheries, and unsustainable use of fossil fuels responsible for global warming illustrate how unrestrained use of resources harms collective well-being. Garrett Hardin referred to this as the tragedy of the commons. He argued that it was the result of population growth and that centralized, coercive solutions are the only way to avoid it.

Though Hardin published his famously pessimistic essay "The Tragedy of the Commons" in 1968, it was as clear then as it is now that tragedies have been avoided in many cases. Forests, subjected to enormous pressure at the end of the nineteenth century in many currently rich countries, are now managed quite well. Assessments and regulations-especially those that establish clearly defined property rights — of fisheries in much of the world have increased global fish stocks. Pollution is an ongoing concern, though government at all scales and in rich, poor, and transitional contexts have, to some extent, adopted policies to mitigate and adapt to climate change. The same story could be told for other commons problems, which we overcome routinely, though solving them is not guaranteed. The puzzle of the commons is that some communities (whether global, national, subnational, or village) successfully overcome commons problems while others do not.

Our argument is that a political-economic approach is necessary to understand this variation in success. Institutions, or rules, are central to the political economy of commons: successful management of commons is always a consequence of formal and informal institutions governing their use. We argue further that successful commons governance has economic, political, and social aspects. The economic aspect includes defining and enforcing property rights, creating markets to appropriately value resources and the environment, and establishing institutions that encourage wealth creation both to enable us to address our environmental concerns and to increase our ability to invest in green technology, infrastructure, and innovation. The political aspect includes establishing polycentric political institutions that enable participation in efforts to manage resource- and global-commons challenges. Polycentrism, which is defined by multiple levels of governance each with autonomy to make rules, is an especially significant concept for understanding commons governance. The social aspect includes encouraging the development of social capital in its various facets such as trust, patience, and individualism. Though individualism (an "I" orientation) is often criticized, we argue that it has many benefits for addressing commons problems. It yields initiative, hard work, and appreciation for private property and markets, each of which is often-though not always - associated with improved commons governance. 
Our empirical studies include several examples of resource commons (forests, fisheries, and minerals) and the global environment. Drawing on a range of evidence and examples, we find that population growth does not inevitably result in tragedies of the resource commons. Rather, our central conclusion is that successful governance of resource commons arises from polycentric political institutions, clearly defined property rights, the presence of markets for goods and services produced from commons as well as markets for pollution, polycentric political institutions, and supportive social institutions, especially trust, patience, and individualism. As for the global environment, we consider GHG emissions, climate-mitigation policy, and adaptation to climate change. Addressing each of these aspects of the global commons requires us to consider property rights, polycentric political institutions, and social institutions such as patience.

Our empirical analysis of these commons yields simple rules for governing commons. Richard Epstein (2009) proposed simple rules for a complex world in response to increasing regulation that in his view undermined economic growth. The simple-rules approach has been applied to inclusive economies, in recognition of the challenges posed by inequality (Tarko 2020). Simple rules are also essential to understanding the resource and global commons, which are increasingly subjected to complicated frameworks relating all manner of variables to improve governance of commons and proposals for enormous increases in subsidies to promote sustainability. What is often lost in conversations about commons is that there is a set of simple rules for improving commons governance-defining and enforcing property rights in response to local conditions, establishing markets for good and services that create the economic incentive to conserve resources, creating polycentric institutions to address commons problems, and public policies that encourage the development of trust, patience, and individualism. Each warrants reconsideration as we as a society consider how to ensure that natural capital translates into economic prosperity.

Much is at stake from successful management of commons. While the Great Enrichment was the result of ideas, as Deirdre McCloskey (2010) has shown so eloquently in her work on bourgeois values, without good institutions and consequent good governance of resources, the rapid-from the perspective of recorded human history-rise in income over the past several hundred years would have been unlikely.

\section{TRAGEDIES ARE NOT INEVITABLE}

One of the goals of this book is to clarify why population growth does not result in a tragedy of the commons. Hardin (1968) famously predicted we would soon use up our natural capital, with devastating consequences. Since 
population has grown exponentially over the past few hundred years, and our resources are fixed (at least if we assume fixed technology), the carrying capacity of the planet is always a looming challenge. Hardin infamously suggested population control as a solution to commons problems; population control is what Hardin meant by "mutual coercion, mutually agreed upon."

Despite its appeal, Hardin's theory does not predict resource use very well (Feeny et al. 1990). There was no "population bomb" (Desrochers and Szurmak 2018). Population in much of the world stabilized, and in many countries, depopulation is considered more of a challenge than population growth (Wattenberg 2004). Optimistic predictions about our collective future receive more support than the pessimistic perspectives once we consider that the substantial improvements in well-being that we have enjoyed over the past few centuries would not have been possible without the substantial, even exponential, increase in the human population.

The predictive failures arise from a conceptually flawed model of the commons, in particular one that presumes that resources must be open access (Frischmann, Marciano, and Ramello 2019). Open access is the absence of any property rights; hence, open-access resources are subject to overuse. The usual approach of institutional economics compares property regimes-especially private property, common property, and state ownership - to understand which is appropriate (Ostrom 1990; Bromley 1991). Common property, which is property owned in common by a group, is often effective in overcoming commons problems, provided locals are able to participate in its governance (Bromley and Cernea 1989). In other situations, commons are privately owned or owned by governments. In any of these situations, institutions shape, constrain, and liberate users of commons.

Another issue with Hardin's perspective is that it presumes centralized government responses are necessary to prevent a tragedy of the commons. The problem with this prescription is that the government is in many instances the reason why commons were destroyed, especially when governments intervened in local, self-governing relations (Brinkley 2020). Government often sees people as prey, and resources as things to consume (Vahabi 2015). Political development is often an effort of communities to evade governments that seek to capture the commons for national development priorities (Scott 1999). A more realistic approach to politics, one that explicitly recognizes the flaws of top-down solutions to commons problems, is necessary to understand the commons (Pennington 2013).

\section{CAPITALISM IS NOT THE PROBLEM}

Capitalism is often invoked as an explanation for ecological and environmental problems. Commons, or creating them, are often viewed as anticapitalist, as 
they are considered opposed to capitalist modes of production (Caffentzis and Federici 2014; Arvidsson 2020). ${ }^{1}$ According to capitalism's critics, expanding markets necessarily means degrading the resource and global commons. But this perspective misdiagnoses the problem. Capitalism and property rights solve commons problems. Our argument is not that capitalism is not bad for the environment but that markets and property rights - the key institutions of capitalism - are the key explanation for governance of commons. Markets help us adapt to commons problems (Anderson 2021).

Before we get to the argument for capitalism, we consider a significant critique of market expansion in the United States during its early era of economic growth. Environmental historian William Cronon's Nature's Metropolis: Chicago and the Great West (2009) provides a wonderfully rich description of the growth of Chicago as markets expanded west in the nineteenth century. It is a masterful historical work that links capitalism - the expansion of markets to degradation of ecosystems.

During the mid-nineteenth century, one of the great objectives of US national policy was to connect the markets of the Midwest, centered on Chicago, with those in California. Politicians were not the only ones who wanted it. Settlers demanded it, and the railroad magnates had much to gain from connecting Chicago, a vibrant shipping hub because of its location on Lake Michigan, to the western frontier. Economists interested in the economic growth of the United States have rightly placed railroads at the center. Although scholars debate how much railroads contributed to economic growth, most agree with Fogel (1964) and Fishlow (1965) that railroads reduced the costs of transporting goods and services and thus contributed to the expansion of the US economy. These proposed benefits do not mean the process was always consensual. Western expansion was coercive, as the development of railroads was accompanied by continued federal violence directed at American Indians and by coerced relocation of tribes in the 1850s that had already been moved to reservations after the 1830 Indian Removal Act started the formal process of moving all indigenous peoples west of the Mississippi River. ${ }^{2}$ The ideology of Manifest Destiny coordinated politicians, settlers, and the army as all three groups, individually and sometimes together, pushed American Indians from their land to forcibly unite markets across the country. The forced removal of American Indians from their homes to reservations and the federal efforts to assimilate them into the culture and institutions of white people (including boarding schools) reflected the desire to create certainty for settlers' property rights by institutionalizing chronic uncertainty of Indian property rights (Alston et al. 2021).

Nature's Metropolis articulates the environmental and ecological tragedy that accompanied the march of railroads westward: unsustainable use of resources, habitat destruction, extinction of species all occurred alongside 
urbanization and expansion of markets. The western landscape transformed as commodities - grain, lumber, meat, and other traded goods - moved across the nation. The association between the expansion of markets - capitalism - and degradation of natural wealth seems clear enough.

Economic historians, especially institutionalists, suggest a cornerstone of capitalism - private property - saved the environment in the western United States. In analyzing the link between conservation and the expansion of the American economy, Libecap (1989) highlights poorly designed federal laws, rather than capitalism, as the source of environmental and ecological harm in the nineteenth century. Farmers, ranchers, and miners each asserted property rights over commons, often informally at first before succeeding in acquiring legal rights.

In the background was a national effort to establish an empire of smallholder farmers. The government waged wars and negotiated treaties that enabled it to acquire over a billion acres of land from 1789 to 1853 . It wanted to use auctions to allocate property rights to land in fee simple, the most complete private property right. Many people squatted on public land because they did not think that they should have to pay the government for land. Congress was generally sympathetic, responding to illegal and extralegal occupation with dozens of laws recognizing squatters' rights from the 1830s through the $1850 \mathrm{~s} .^{3}$ Squatters' rights required that people prove they lived on the land and had paid something for it. Then the Homestead Act was signed by Abraham Lincoln in 1862. Unlike the squatters'-rights regime, the Homestead Act gave land away for free, and homesteaders were not required to prove that they were bona fide settlers who occupied land in search of a new occupation. Rather, homesteads were meant to encourage settlement west of the Mississippi.

The homestead laws were ultimately successful in encouraging migration, as millions entered patents for 160 acres in fee simple under the homestead law. They were also in many ways poorly designed. The land west of the Mississippi River was more arid and less suitable for agriculture than the Midwest, and farmers had to figure out more appropriate techniques to productively farm in the desert. In the meantime, many neglected to practice appropriate conservation techniques, leading to ecological damage that ultimately reduced the productivity of their farms (Libecap and Hansen 2002). The Dust Bowl in the 1930s was in part a consequence of poor conservation techniques. Small farmers, whose land was obtained from the federal government at little explicit cost, were more likely to suffer busts than larger farms were because farmers with more land had incentives to adopt sound crop-rotation practices. The farmers with the larger initial allotment of land could afford to rotate crops out of production, while those with smaller allotments - many of whom acquired a relatively small homestead of 160 acres for farming in the inhospitable climate west of the Mississippi River-felt a need to farm on all their 
land to stay in business. Unsustainable farming reflected a policy failure: the government had reduced the price far below the market value of land and in the process had encouraged inefficient risk taking that ultimately resulted in environmental and ecological problems.

The push for farms in the arid West also conflicted with evolving norms on the open range, where ranchers drove cattle over long distances. Homesteaders presented a problem because they were encroaching on land used for ranching. Congress did not provide any clear path for ranchers to establish property rights, even collective property rights, over their land. The result was contestation over the commons, with ranchers and farmers sometimes fighting over property.

Ranchers took things into their own hands. Anderson and Hill's (2004) aptly titled The Not So Wild, Wild West: Property Rights on the Frontier shows that ranchers established their own associations - cattlemen's associations - that were effective in managing access to the open range. These associations regulated ranching activities in entire states, in particular Montana and Wyoming. They brought together ranchers to deliberate collectively about what their rules ought to be, such as those governing how many cattle each rancher could bring to the range and how ranchers would deal with trespassers. These associations presided over the expansion of the industry and dealt with disputes, all while avoiding the all-important problem that too many cattle would lead to a tragedy of the commons. Markets were not the problem. In fact, the expansion of markets put in motion the creation of property rights. Cattle were valued in markets, and so the open range, which was necessary to ensure the cattle were well fed and healthy, had to be conserved. Cattle owners developed their own property rights that contributed to sustainable herd size as the market signaled to them the value of doing so.

The gold rush, which commenced in California in 1848, is another example of how definition and enforcement of property rights addressed (albeit imperfectly) commons problems. Miners were able to increase production because there were so many of them. But property rights were poorly defined, and hence mining was often wasteful and many miners went broke. Miners had to establish governance institutions to avoid the tragedy. Their mining districts and courts of law to adjudicate disputes over placers' claims had almost all the features of a government. They had no legal authority; but the miners' courts were enough to provide order among miners. It was not a perfect system, and the property institutions established by miners were far from complete, which is why the miners welcomed federal law, which came in 1866 with the General Mining Act. The more complete definition and enforcement of property rights created a legal framework-miners' law became codified-and with the change, the industry expanded and modernized. Mining spread across the country as gold production declined in California. 
American bison are a more complicated example. Bison roamed in the middle part of what is currently the United States - we now call it the Great Plains - for millennia before Europeans arrived. Many indigenous tribes of North America relied on buffalo for subsistence. American Indians had property rights over bison, and their traditional policing institutions regulated the hunts. Long before Europeans arrived, American Indians developed property institutions whereby they marked their arrows so that the most prolific hunters could have their choice of cut of meat (Benson 2006).

Bison came close to extinction by the end of the nineteenth century as railroads and settlers marched west, backed by the US Army. Herds that once numbered in the millions were now in the hundreds. Property rights could not save the buffalo: American Indians already had property rights to buffalo. What they did not have was the power to exclude the encroaching Americans, especially after the Civil War ended in 1865. As the value of land for railroads increased, rational railroaders, with support from the US military, killed off buffalo in large numbers. Another important change was the increase in market demand for buffalo hides (Taylor 2011). In a sense, markets were the problem because the railroads were more valuable than the buffalo and because demand for buffalo hide had increased. But markets and the creation of property rights were also the solution. Incentives to conserve buffalo increased as their stock declined, and the herd eventually recovered - in part because property rights over them were assigned (Hill 2014).

The tragedy of the commons is not inevitable. Nor are capitalist institutions responsible for resource degradation. To the contrary, definition and enforcement of private property rights contribute to resource abundance or, in the case of bison, resource recovery. But government can fail to assign the most appropriate property rights, or it can prioritize activities that are inappropriate for a region. Government, not capitalism, is typically the problem, not only when it fails to act or it establishes the wrong institutions, but when political decision makers subsidize behavior that results in mismanagement of the commons.

\section{WHY POLITICAL ECONOMY?}

To make the two points above - that population is not a problem and that capitalism is a solution - we develop a political economy of the commons. Political economy can be defined as a concern with the emergence and consequences of institutions. Following North (1990) and Ostrom (2005), institutions can be thought of as rules that liberate and constrain individuals and shape their pursuit of what they want. What they want may be what benefits them most, or they may be concerned with the well-being of others. Human behavior cannot be reduced to selfish desires, an idea that goes back to Adam Smith's understanding of human behavior and that the humanomics approach, with 
its appreciation for how ethics informs human behavior, has shown so clearly (Smith and Wilson 2019; McCloskey 2016; Smith 2012; McCloskey 2008).

Both formal and informal institutions matter. Formal institutions include laws, constitutions, and regulations. Informal institutions include norms, working rules, conventions, social networks, and culture. The usual economic approach is to consider how institutions contribute to prosperity and, more particularly, the extent to which formal rules, such as property rights and contract law (North and Thomas 1973; Acemoglu and Johnson 2005), versus informal ones, such as cultural appreciation of entrepreneurs (Clark 2008; McCloskey 2010; Mokyr 2017), contribute most to economic well-being. Regardless of the specific institutions one focuses on, institutionalists share an appreciation for quantitative questions: it is concerned with how much we have and how we arrived here (Allen 2011; McCloskey 2013).

Institutional analysis is inherently comparative. The reason is that to understand the consequences of any institution requires us to consider situations without it. Comparative political economy makes comparisons, typically across countries, more explicit. It has many names: new comparative economics (Djankov et al. 2003), comparative historical political economy (Boettke et al. 2005; Boettke, Coyne, and Leeson 2013), or simply comparative political economy. Its central idea is that it is necessary to consider institutions across countries to explain variation in economic well-being.

Political economy can also be defined by its concern with information and incentive problems. Given realistic challenges to the functioning of institutions, political economy considers which institutions best address imperfect knowledge, bounded rationality, and opportunism (Pennington 2011). Institutions also ought to reduce conflict and establish and maintain social order while attempting to promote the common good (Cowen 2021). Solutions might include a minimal state or simple rules that provide a framework, such as private property and limited government, to address challenges and resolve differences (Epstein 2009).

Pennington (2013) initiated consideration of the political economy of commons in the classical liberal tradition, with emphasis on the risks associated with centralized solutions to commons governance. It is a necessary complement to Elinor Ostrom's emphasis on decentralized solutions to commons problems. We add to these perspectives by explicitly considering commons governance as having economic, political, and social aspects. The view that achieving the common good has economic, political, and social aspects was initially developed to explain the wealth of nations. Boettke (2001) uses this tripartite approach to understand the economic well-being of nations and the reform of command economies. Boettke's central conclusion is that countries with political constraints and liberal economic institutions-for example, private property rights, contracts, and commercial law-and sup- 
portive social institutions, such as trust, tend to be wealthier. The failure to transition from communism toward a capitalist economy can be attributed to a combination of economic, political, and social challenges. Meeting all three challenges is necessary to prosper. For example, private property rightsformal, legal institutions - are more effective when social institutions support them (Williamson 2009). Sustainable use of commons, including at the local level with resource commons and at the level of global commons, also has economic, political, and social aspects.

The central economic aspects include the definition and enforcement of property rights and the presence or creation of markets for resources. Environmental markets also include those for pollution, such as cap and trade. The political aspect has two parts: an institutional aspect, most significantly polycentrism and democracy, and a partisan and bureaucratic aspect, which focuses on the specific interests of groups, politicians, and bureaucrats. The most critical parts of the social aspect, we argue, are social capital, in particular trust and patience, and a culture of individualism.

This framework provides the basis for simple rules. The first rule is to define and enforce property rights in response to local conditions. The second is to create markets wherever possible to price environmental and ecological goods and to create markets for harms, as in emissions-trading markets. The third rule is to establish polycentric governance institutions that provide localities with the autonomy to define specific rules for addressing resource- and global-commons problems. The fourth rule is to develop social capacity to address commons problems indirectly by facilitating social trust, society-wide patience, and individualism.

\section{CLASSICAL LIBERALISM AND THE POLITICAL ECONOMY OF SIMPLE RULES}

The simple rules that emerge from classical liberal theory and empirical evidence on efforts to manage commons attest that the tragedy of the commons is very unlikely in the presence of clearly defined and enforceable property rights, markets to allocate resources, locally inclusive and decentralized political institutions, and social institutions that support cooperation and encourage individual initiative. When these factors are present, even explosive population growth will not result in a tragedy of the commons. When there is a tragedy of the commons, the problem is generally with the institutions, rather than the number of people using the resource. Our conclusions are reminiscent of Adam Smith's classical liberalism, Elinor and Vincent Ostrom's work, and the public choice literature, with its recognition of the problems with the centralized state.

The classical liberal perspective is often questioned when it comes to issues of ecology and environment, even by those who recognize the virtues of 
markets. For example, Kenneth Arrow's introduction to an important volume on sustainability began with an appreciation for property. Arrow noted that when private property rights are defined and enforced, prices rise in response to changes in demand and supply and consumers shift to more abundant resources, all of which suggests that we will enclose commons to conserve them and that, eventually, the prices of fossil fuels will increase enough that greener alternatives will become more competitive in markets. Arrow (1996) went on to observe that

there is abundant evidence that the private property system is frequently not working as it is supposed to. Indeed, with regard to many branches of life, the very idea of property in the ordinary sense is practically and conceptually difficult. Fish and wild animals are mobile; they do not well accord with ordinary property concepts, for they cannot be identified with property rights defined, for example, by locality. They fall to some extent into the categories of free-access goods, and both theory and practice show the dangers of overutilization. The nineteenth century showed the possibility of extinction of some aquatic mammals and near-extinction of others, such as sea-otters. The extinctions were not even in the long-run interest of the human predators, let alone of human beings as a whole, even if one granted no rights to the animals themselves. (xiii-xiv)

The volume in question proposed the socioecological systems (SES) approach, with its enormous list of variables that contribute to successful commons governance, as an organizing framework for studying the commons (for useful reviews of the SES approach, see Janssen and Ostrom 2006; Ostrom 2009; Anderies, Janssen, and Ostrom 2004; Hanna, Folke, and Mäler 1996).

The SES approach is full of insights. And we agree with Elinor Ostrom and her colleagues that there are no panaceas when it comes to resource governance (Ostrom 2007; Ostrom, Janssen, and Anderies 2007). Yet with all due respect to Kenneth Arrow, historically and in the contemporary world and in most of the cases he mentioned, private property has indeed been the way the problem is solved. The volume also fails to make explicit the simple rule that in order for government to figure out what works best, communities at multiple scales must be included in the decision-making process. The combination of defined and enforced property rights, polycentrism, and social capital results in solutions to the tragedy of the commons. Neither capitalism nor population growth is the problem; rather, the problem is one of institutional design and of overcoming political challenges and of designing public policies.

We consider institutionalism to be fully within the realm of classical liberalism. Though classical liberals appreciated the importance of constitutional rules to enable markets, the approach of institutional economics explicitly considers how the presence or absence of certain types of rules affects outcomes of interest. The legal institutionalists focus on the significance of legal rules for 
the success of modern capitalist economies. Pistor (2019) explains that assets must be "coded" to become capital. The process of coding assets into capital involves the assignment of legal rights and obligations to assets that enable it to become part of market exchange. An important example of such coding is the assignment of property rights to individuals through the legal process (the example of assignment of property rights in fee simple to settlers discussed above is an example of coding assets into capital). Hernando de Soto (2000) makes a similar argument in his praise of legal centralism - the assignment of property through a formal judicial system - in his otherwise-libertarian defense of private property. Each recognizes the important role of law. Laws - in particular, some system of ownership — are central to the commons. But contra de Soto, private property is not necessary. And contra Pistor, the law does not necessarily lead to the undoing of capital, though in some cases there is a mismatch between how assets have been coded into law and new challenges as they arise. Rather, law provides ongoing solutions, provided there is a framework for law to adapt, which is where political institutions such as polycentrism come in-that is, political frameworks that enable such adaptation of law, and policy, to new circumstances.

Epstein's (2009) simple rules are a useful framework for considering commons, though we see a need to adapt it somewhat. According to Epstein, the first four rules, which regulate human interactions in ordinary social life, concern the autonomy of the individual, property, contract, and tort, and they protect entitlements over all resources, both human and natural. A backstop rule is the requirement of payment of just compensation when private or public necessity dictates it. These simple rules are then used to understand topical areas of law including collective bargaining, unjust dismissal, employer discrimination, comparable worth, and environmental protection. Deviations from these simple rules result in social strife and economic dislocation.

Like Epstein, we find simple rules are critical, though our simple rules differ for the following reasons. Missing from the simple rules is the polycentrism of the Ostroms and a more nuanced analysis of property. The simple rule is not that private property is necessary, but that property rules must reflect local conditions. Markets also must be established; and that requires a legal and administrative framework, which requires the state. And left out of Epstein's simple rules are those that encourage the social institutions that enable improvements in well-being.

The last type of rule is closely related to the ordoliberal endorsement of the use of government to create a social framework for markets. Ordoliberals - a group that emerged in the early twentieth century alongside Friedrich Hayek and Ludwig von Mises and the other Austrian economists - did not take a "supportive culture" as given; they thought the state has a role in shaping culture (Kolev 2015). Their view is unlike the Hayekian view of culture, which sees 
culture as the ultimate spontaneous order (Caldwell 2000). Our approach is even simpler than the ordoliberal view: encourage trust, patience, and individualism. The individualism we speak of is not what Bromley (2019) calls possessive individualism: myopic love for oneself even when that self-love comes into conflict with the common good. Rather, the individualism we have in mind entails the entrepreneurship and innovation and self-determination that is associated with growth. Encouraging consideration for one's community does not mean eliminating individualism per se but possessive individualism in particular.

\section{AN OVERVIEW OF THE BOOK AND THE EMPIRICAL STUDIES}

Chapter 2 presents the population-bomb argument, considers critics of the population-bomb view, and then introduces the political-economic framework that is then used to consider various cases.

Chapters 3 through 6 are organized by type of commons. In Chapter 3, we review the vast evidence from the literature on deforestation, finding deforestation is likely to be mitigated with better definition and enforcement of property rights, greater wealth, deeper democracy, polycentrism, and supportive social institutions, including trust. Forests are valuable, and while naïve theories of institutional change suggest that people will adopt more efficient institutional arrangements to capture the substantial value of forests, we know that many forests throughout the world are poorly managed. The ongoing costs of deforestation are enormous: local economies are made worse off, indigenous forest dwellers are left vulnerable, environmental and land quality decline, and in some situations, migration results in conflict and violence.

We consider deforestation at multiple scales: community, regional, and national. It is not an inevitable consequence of increasing demand for forest products. Monocausal explanations for deforestation based on population ultimately fail. Capitalist countries and wealthier ones have largely seen reversals, though the relationship with expansion of markets is complicated, as global demand surely does contribute to deforestation. Deforestation is a consequence of bad institutions, not capitalism: poorly defined and enforced property rights; political institutions that enable rent-seeking by interest groups and prevent local groups from participating in shared governance; and deficits in social capital, such as trust and individualism. There are also cultural dimensions to deforestation, including links between individualism and reforestation. Land-tenure security, locally responsive political institutions, and social capital contribute to successful reforestation, and so avoiding deforestation is less a matter of establishing coercive institutions than of establishing responsive ones and the rule of law. 
Chapter 4 considers the political economy of inshore and offshore fisheries. Even on the high seas, the costs of regulating fisheries are not so great as to result in tragedies of the global fishery commons. Global fisheries are under pressure from unregulated commercial fishing, but, as with deforestation, institutions rather than population pressure determine when use of inshore and ocean fisheries is sustainable. We consider several cases: salmon fishing in the Pacific Northwest, with emphasis on how indigenous tribes defined and enforced property rights over salmon, their most important capital asset; lobster fisheries off the Atlantic coast in the northeastern United States; global fisheries management; and pirate fishing on the high seas.

The examples of salmon and lobster fishing show the importance of property rights, the significance of self-governance, and why polycentric institutions that account for local institutions can improve fisheries governance. These two cases - and the social order of lobster gangs in particular - also illustrate that strong social norms often contribute to effective fisheries governance even in the absence of rigid formal rules. Each lobster gang has territorial rights, enforced through social norms. Still, definition and enforcement do not ensure that a fishery will be managed effectively, as access still needs to be regulated. For deep-sea fishing (far from the coast), definition is not much of an issue, but enforcement is. The ocean provides many places to hide, as we see from the case of fish pirates. Some nations enforce the law more than others do, so the problem is understanding what leads such nations to contribute to the public good. There is also the issue of pressure coming from increasing consumption, which depends in part on population. As with forests, population is but one source of pressure on fisheries, and with the right institutions, it is far from an insurmountable challenge.

In Chapter 5, we describe how miners avoid the tragedy of the commons. In three case studies, we consider the evolution of institutions governing mining in the United States: gold mining in California during the gold rush; the evolution of unitization agreements governing oil and gas reservoirs; and the evolution of rules governing hydraulic fracturing (or fracking - the extraction of gas and oil from shale). The gold rush is an important case because it shows that definition of property rights is significant for avoiding common-pool losses, that the miners' property rights were not as clearly defined as some anarcho-capitalist accounts suggest, and, most fundamentally, that population pressure resulted in clearly defined and enforced formal property rights, thus addressing the commons problem with mining. More generally, the successful capture of gold, and the avoidance of a free-for-all, reflected economic factors (increasing mine values), political ones (the interests of bureaucrats), and social ones (all miners understood property rights and were better at managing their conflicts when they had homogeneous, small communities). This shows that a variety of factors contributed to successful commons governance despite 
the enormous increase in people seeking to strike it rich in the first years of the gold rush. The case of conventional oil and gas illustrates how property rights - in particular, unitization agreements - can address commons problems. The issue with fracking is different, as it presents externalities that have been addressed through regulation. The question then becomes whether those regulations can adapt. We show that they have adapted and that the extent of regulations has much less to do with population than with local and state political and economic conditions.

Chapter 6 addresses global climate change, including GHG emissions, mitigation policy, and adaptation to climate change. Global temperatures are the highest they have been in a thousand years, with consequences for rising ocean levels and more extreme weather. The enormous economic and human-health impacts of global warming might offset the enormous improvements in income per capita from the Great Enrichment, which started in the middle of the eighteenth century. Any credible economic analysis must consider both the benefits from productivity (the resulting technology and knowledge that help address climate change problems) and its external effects, including climate change.

We consider GHG emissions, climate change mitigation, climate change adaptation, and climate justice. Both mitigation and adaptation are necessary to deal with emissions and climate change. It may be more challenging to internalize benefits from policies that mitigate emissions than from those that encourage adaptation (the former has global benefits, and the latter may have local benefits). Climate justice - and its relationship to benefit-cost analysis of mitigation and adaptation - concerns what we ought to do to address climate change and how questions of equity relate to those of efficiency (as all benefitcost analysis is necessarily a question of efficiency). ${ }^{4}$ What emerges is clear: even for advocates of climate justice, market mechanisms should be preferred to command-and-control policies. Polycentrism is increasingly recognized as significant in fighting climate change. Capitalist countries are also reversing patterns of GHG emissions. The central question is how to design policies to encourage business to invest in greener technologies. Still, an ongoing challenge is that polycentrism is subject to political-market failures, including local power relations that undermine climate change progress. There are no panaceas as far as political institutions are concerned, though there are good reasons to prefer polycentric to centralized ones for mitigating climate change and adapting to its consequences.

In analyzing these four commons, the empirical studies recognize the interrelationships among them. For example, a 2019 Intergovernmental Panel on Climate Change report projected that the loss of Arctic sea would result in losses to fisheries that would reduce food security. ${ }^{5}$ The mechanism is that carbon emissions result in ocean warming, acidification, and oxygen loss, all 
of which hurt fisheries. Similarly, deforestation is related to climate change. This is the idea behind the reducing emissions from deforestation and forest degradation and forest enhancement (REDD+) program. The program is explicitly based on the link between the capacity of forests to absorb carbon and mitigate global warming. It explicitly recognizes that governments and voluntary associations are necessarily linked in polycentric settings. Thus, global fisheries and global deforestation are each linked to the global environment. We add that what sets this in motion is the definition and enforcement of property rights over forests. Thus, addressing the consequences of climate change and improving global fisheries depends in part on property rights to forests.

Chapter 7 derives the simple rules for sustainability from classical liberal theories of political economy and from our empirical studies. Whereas Elinor Ostrom's research considered self-governance of commons, a political-economic approach highlights the political challenges with managing commons. One lesson is that population does not tell us much about the commons problem. Rather, the focus must be on institutions. Once we appreciate the role of institutions, issues such as institutional stickiness, which concerns the challenge of transplanting institutions from one context to another, come into play. Another lesson is that polycentric governance, rather than the centralized responses preferred by Hardin, is more likely to alleviate common problems. In addition, policies that help build social capital (including trust and patience) have collateral benefits for governance of commons.

\section{NOTES}

1. Sociologists' and historians' view of commons as anticapitalist can be contrasted with Benkler's work on sharing spectrum, which shows that some of the world's most massive companies, including telecommunications companies, can and do share resources, while remaining capitalist. More generally, the sharing economy, or what Munger (2018) calls the economy of tomorrow, is a capitalist enterprise.

2. Though the act stated that tribes had to consent to relocation, President Andrew Jackson ignored these provisions, waging wars and committing atrocities rather than negotiating with the southern tribes.

3. Formally, they were known as preemption rights, as they allowed those who settled on public land before public land auctions to acquire land for a reduced price.

4. The defining feature of benefit-cost analysis is monetization of all relevant impacts of public policies (Boardman et al. 2017).

5. "Special Report on the Ocean and Cryosphere," https://www.ipcc.ch/srocc/. 